\title{
Identification of Two New Genes Conferring Resistance to Colletotrichum acutatum in Capsicum baccatum
}

\author{
P. Mahasuk, P. W. J. Taylor, and O. Mongkolporn
}

First author: Center for Agricultural Biotechnology, Kasetsart University, Kamphaeng Saen Campus, Nakhon Pathom 73140 Thailand; second author: BioMarka/Center for Plant Health, Faculty of Land and Food Resources, The University of Melbourne, Victoria 3010 Australia; third author: Center for Agricultural Biotechnology and Department of Horticulture, Kasetsart University, Kamphaeng Saen Campus, Nakhon Pathom 73140 Thailand.

Accepted for publication 28 April 2009.

\begin{abstract}
Mahasuk, P., Taylor, P. W. J., and Mongkolporn, O. 2009. Identification of two new genes conferring resistance to Colletotrichum acutatum in Capsicum baccatum. Phytopathology 99:1100-1104.

Resistance to anthracnose, caused by Colletotrichum capsici and $C$. acutatum, was investigated in Capsicum baccatum PBC 80 and PBC1422 and $C$. chinense PBC932. Mature green and ripe fruit were inoculated with 13 isolates of the two Colletotrichum species PBC 80 contained the broadest spectrum of resistance to both Colletotrichum species because none of the isolates were able to infect the genotype. At both fruit maturity stages, PBC1422 was infected by only Colletotrichum acutatum. PBC932 at ripe fruit stage was infected by both $C$. capsici and $C$. acutatum, except for one isolate, 158ci, that did not infect PBC932.

PBC932 at the mature green fruit stage was infected by only C. acutatum. An intraspecific cross between $\mathrm{PBC} 80$ and $\mathrm{PBC} 1422$ was developed to determine inheritance of resistance to $C$. acutatum. Anthracnose resistance was assessed at mature green and ripe fruit stages using 0 to 9 disease severity scores. Frequency distribution of the disease scores in the $\mathrm{F}_{2}$ and $\mathrm{BC}_{1}$ populations suggested a single recessive gene responsible for the resistance at mature green fruit stage and a single dominant gene for the resistance at ripe fruit stage. Linkage analysis between the two genes identified in both fruit maturity stages showed the genes to be independent. Based on phenotypic data, the two newly identified genes, co4 and Co5, from PBC80 appeared to be different loci from the col and co2 previously identified from PBC932 and will be valuable sources of resistance to anthracnose in chili breeding programs.
\end{abstract}

Anthracnose is a serious disease to chili production in the tropics and subtropics worldwide. Significant annual yield losses have been reported in Korea (US\$100 million) and India (US\$1.33 million) (9). Anthracnose is caused by a complex of Colletotrichum spp., with three main species (Colletotrichum capsici, C. gloeosporioides, and C. acutatum) having been reported as key pathogens causing chili anthracnose in several countries such as China, India, Taiwan, Vietnam, Brazil, and Thailand (9, 10,14). Resistance to anthracnose has been identified in a number of chili genotypes, including Capsicum chinense Jacq. 'PBC932' and C. baccatum L. 'PBC80' and 'PBC81' $(4,9,10,12,16)$.

These resistant lines combined with another six Capsicum genotypes were assessed for differential reactions to 11 Colletotrichum capsici isolates (10). Based on qualitative differential host reactions (i.e., ability to infect or not infect specific genotypes) three pathotypes of $C$. capsici (PCc 1, PCc 2, and PCc 3) were identified in Thailand. The key Capsicum species giving differential reactions was Capsicum chinense, whereas all genotypes of C. baccatum species were not infected and all genotypes of $C$. annuum and frutescens were infected (10). According to the study of Montri et al. (10), C. baccatum appeared to possess a broader spectrum of resistance than $C$. chinense. However, this pathotype study was limited to Colletotrichum capsici isolates and not $C$. acutatum, which is also an important pathogen of Capsicum spp.

The inheritance of resistance to anthracnose has been studied in chili fruit of several populations derived from different sources of resistances, using various Colletotrichum spp. and different disease assessments $(4-7,12,15)$. A significant finding was that dif-

Corresponding author: O. Mongkolporn; E-mail address: orarat.m@ku.ac.th

doi:10.1094/PHYTO-99-9-1100

(C) 2009 The American Phytopathological Society ferent genes controlled the resistances at different fruit maturity stages. Two recessive genes, col and co2, from PBC932 were responsible for the resistance at mature green and ripe red fruit stages, respectively $(9,12)$. The genes $c o l$ and $c o 2$ were linked at $\approx 25$ centimorgans apart (9).

The most important Capsicum sp. in the world is Capsicum annuum; however, no commercial cultivar in this species has been identified containing resistance to Colletotrichum spp. To introgress resistance into $C$. annuum elite cultivars, Capsicum breeders have utilized $C$. chinense and $C$. baccatum as sources of the resistance since the resistant lines were first identified by the AVRDC (The World Vegetable Center, formerly Asian Vegetable Research and Development Center, Taiwan) in 1998. This study aimed to evaluate the spectrum of resistance to anthracnose caused by Colletotrichum capsici and $C$. acutatum on the key resistant genotypes of Capsicum chinense 'PBC932' and $C$. baccatum 'PBC80', and to study the inheritance of resistance to anthracnose in $C$. baccatum intraspecific populations at both mature green and ripe fruit stages.

\section{MATERIALS AND METHODS}

Pathogenic study. $C$. chinense PBC932 and two $C$. baccatum genotypes, $\mathrm{PBC} 80$ and $\mathrm{PBC} 1422$, were inoculated with single spore isolates of seven Colletotrichum capsici and six $C$. acutatum isolates (Table 1). Of the seven C. capsici isolates, six originated from Suphan Buri Province of western Thailand and were classified as PCc1 (pathotype 1) by Montri et al. (10). One isolate, $158 \mathrm{ci}$, was of unknown origin in Thailand. All C. acutatum isolates originated from Chiang Mai Province of northern Thailand. Ten plants of each genotype were grown in $40-\mathrm{cm}$ plastic pots in a shade house from January to September 2006. The inoculation was performed following the injection method 
developed by Kanchana-udomkan et al. (2). Five fruit each of mature green ( $\approx 35$ to 40 days after flowering) and ripe $(\approx 45$ to 50 days after flowering) maturity stages were harvested from each chili genotype for inoculation. Anthracnose symptoms were assessed at 12 days after inoculation (DAI) by estimating percent lesion size in relation to the overall fruit size of each fruit following the disease scales developed by Montri et al. (10). Mean percent lesion size of the five fruit was then converted to the 0 to 9 disease scores as described by Montri et al. (10). The pathogenicity experiment was performed in a completely randomized design with five replications (fruit). Fruit of Capsicum annuum cv. Bangchang (the susceptible check) at mature green and ripe stages was inoculated with all isolates. The experiment was repeated three times, and all provided identical results. Data from one experiment are shown in the results.

Inheritance of the resistance to Colletotrichum acutatum in Capsicum baccatum PBC80. Plant materials. An intraspecific cross was made between two C. baccatum genotypes, PBC80 and $\mathrm{PBC} 1422$. The PBC80 resistant genotype was assigned in this study as $\mathrm{P}_{1}$ and the $\mathrm{PBC} 1422$ susceptible genotype was $\mathrm{P}_{2}$. Reciprocal $\mathrm{F}_{1}$ was also generated. $\mathrm{F}_{2}, \mathrm{BC}_{1} \mathrm{P}_{1}$, and $\mathrm{BC}_{1} \mathrm{P}_{2}$ populations consisting of 220, 90, and 90 plants, respectively, were produced. Ten plants each of $\mathrm{P}_{1}, \mathrm{P}_{2}$, and $\mathrm{F}_{1}$; the $\mathrm{F}_{2}$; and both $\mathrm{BC}_{1}$ populations were grown in the field at the Tropical Vegetable Research Center (TVRC), Kasetsart University, Kamphaeng Saen Campus from December 2007 to May 2008. Five chili fruit of each mature green and ripe stage were harvested from each single plant for inoculation. Fruit of both fruit stages were harvested from the same flower set of the same plant; therefore, the mature fruit was harvested $\approx 10$ days before the ripe fruit for inoculation. Because all chili plants did not flower at the same time, the fruit harvesting was performed four times for all populations.

Assessment of resistance to anthracnose. The detached fruit was inoculated with Colletotrichum acutatum isolate MJ5. The inoculation and disease evaluation was performed as previously described. Anthracnose symptoms were assessed at 12 DAI as previously described. Fruit of Capsicum annuum cv. Bangchang (the susceptible check) inoculated with sterilized water was used as negative control, and fruit inoculated with Colletotrichum acutatum MJ5 was used as positive control.

Genetic analysis. Distributions of disease scores at each fruit maturity stage (green and ripe) were analyzed. Resistant (R) and susceptible (S) phenotypes were classified based on the parental performance. Frequency of each phenotype was determined and the segregation ratio of $\mathrm{R}$ to $\mathrm{S}$ was analyzed to fit a Mendelian segregation ratio using a $\chi^{2}$ test.

Linkage between genes that controlled the resistance at green and red fruit was analyzed by considering the segregation of possible phenotypic combinations for each pair of genes. Segregation of the phenotypic combination for each pair of genes was analyzed to fit a ratio based on the Mendelian law of independent assortment using a $\chi^{2}$ test. If the segregation did not fit a Mendelian ratio, then recombinant phenotypes which resulted from crossing over of the two genes were calculated.

\section{RESULTS}

Spectrum of resistance to anthracnose of three Capsicum genotypes. After being inoculated with the 13 isolates of $\mathrm{Col}$ letotrichum capsici and C. acutatum, only Capsicum baccatum PBC80 was not infected at both fruit maturity stages (Table 1). PBC1422 was infected by only Colletotrichum acutatum, with a mean percent lesion size of 5 to 15 (mostly score 5). At the ripe maturity stage, Capsicum chinense PBC932 appeared to be highly susceptible to almost all Colletotrichum isolates (mean percent lesion size, 22 to 65 ; scores, 7 to 9), except with $C$. capsici $158 \mathrm{ci}$, which could not infect (score 0 ). At the green maturity stage, none of the Colletotrichum capsici isolates could cause infection (Table 1). In this pathogenicity study, $\mathrm{PBC} 80$ showed the broadest spectrum of resistance (immune resistance) to all 13 isolates of $C$. capsici and C. acutatum.

Inheritance of resistance to $C$. acutatum in Capsicum baccatum PBC80. Anthracnose resistance at mature green fruit stage. Anthracnose disease scores, as evaluated on mature green fruit at $12 \mathrm{DAI}$, in all $\mathrm{PBC} 80$ and $\mathrm{PBC} 1422$ plants were 0 and 5, respectively (Table 2; Fig. 1). All $\mathrm{F}_{1}$ plants, as well as the recipro-

TABLE 1 . Anthracnose severity evaluated as disease scores on a 0 to 9 scale of chili genotypes PBC932, PBC80, and PBC1422 at 12 days after inoculation with 13 isolates of Colletotrichum spp.

\begin{tabular}{|c|c|c|c|c|c|c|c|c|c|c|c|c|c|c|}
\hline \multirow[b]{2}{*}{ Cultivars } & \multirow[b]{2}{*}{ Fruit stage $^{\mathrm{a}}$} & \multicolumn{7}{|c|}{ Colletotrichum capsici } & \multicolumn{6}{|c|}{ C. acutatum } \\
\hline & & F8-1A & F8-2A & F8-3A & F8-3B & $\mathrm{F} 8-4 \mathrm{C}$ & F8-5B & $158 \mathrm{ci}$ & MJ2 & MJ4 & MJ5 & MJ10 & 111 & 115 \\
\hline \multirow[t]{2}{*}{ PBC932 } & G & 0 & 0 & 0 & 0 & 0 & 0 & 0 & 7 & 9 & 9 & 9 & 7 & 9 \\
\hline & $\mathrm{R}$ & 9 & 9 & 9 & 9 & 9 & 9 & 0 & 7 & 9 & 9 & 9 & 9 & 9 \\
\hline \multirow[t]{2}{*}{$\mathrm{PBC} 80$} & G & 0 & 0 & 0 & 0 & 0 & 0 & 0 & 0 & 0 & 0 & 0 & 0 & 0 \\
\hline & $\mathrm{R}$ & 0 & 0 & 0 & 0 & 0 & 0 & 0 & 0 & 0 & 0 & 0 & 0 & 0 \\
\hline \multirow[t]{2}{*}{$\mathrm{PBC} 1422$} & $\mathrm{G}$ & 0 & 0 & 0 & 0 & 0 & 0 & 0 & 5 & 5 & 5 & 5 & 5 & 5 \\
\hline & $\mathrm{R}$ & 0 & 0 & 0 & 0 & 0 & 0 & 0 & 3 & 5 & 5 & 5 & 5 & 5 \\
\hline
\end{tabular}

${ }^{a} R=$ ripe fruit maturity stage and $G=$ mature green fruit stage.

TABLE 2. Phenotypic segregation for resistance $(\mathrm{R})$ and susceptibility $(\mathrm{S})$ to anthracnose as inoculated by Colletotrichum acutatum 'MJ5' at mature green fruit stage in 'PBC80' $\left(\mathrm{P}_{1}\right)$, 'PBC1422' $\left(\mathrm{P}_{2}\right), \mathrm{F}_{1}, \mathrm{~F}_{2}$, and $\mathrm{BC}_{1}$ populations as evaluated by contingency $\chi^{2}$ values to fit a Mendelian 1:3 single gene model in the $\mathrm{F}_{2}$ and $1: 1$ in the $\mathrm{BC}_{1} \mathrm{P}_{1}$ populations ${ }^{\mathrm{a}}$

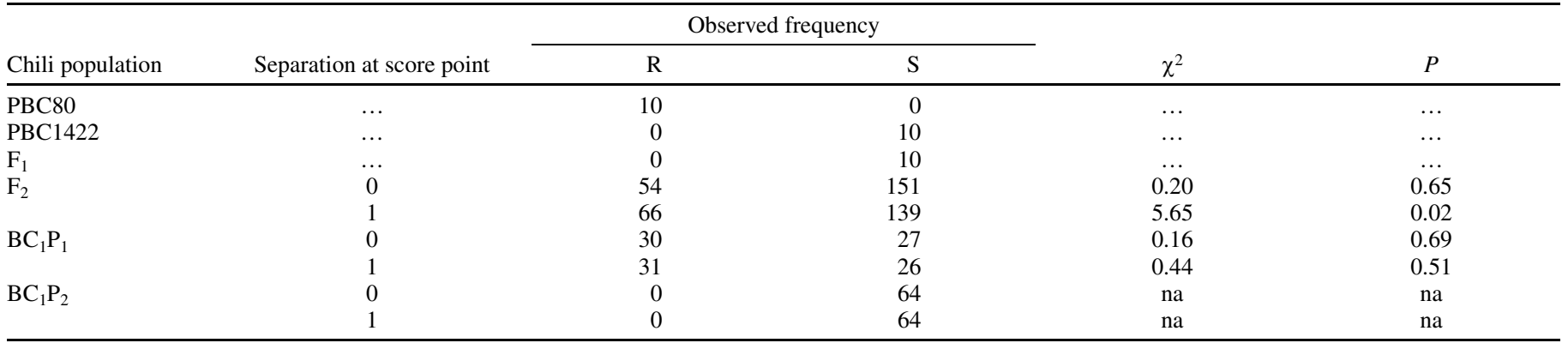

${ }^{\mathrm{a}}$ na $=$ not applicable. 
cal $F_{1}$ (data not shown), appeared to be susceptible to anthracnose, resembling the host reaction of the susceptible parent PBC1422 (Table 2; Fig. 1).

The disease score distribution in the $F_{2}$ was skewed toward $\mathrm{PBC} 1422$, suggesting that resistance at mature green fruit stage was a recessive trait. The segregation of the disease scores in the $\mathrm{F}_{2}$ suggested a single gene model with two phenotypic classes, $\mathrm{R}$ and S. A $\chi^{2}$ test fitted a 1:3 Mendelian segregation ratio for $\mathrm{R}$ and $\mathrm{S}$ at two phenotypic separation points, including scores 0 and 1 (Table 2). Although the goodness-of-fit test accepted the separation point at either score 0 or 1 , the better fit was derived when the separation point was at the score $0(P=0.65)$.

The segregation of $\mathrm{R}$ and $\mathrm{S}$ in both $\mathrm{BC}_{1}$ populations at the same separation points as in the $\mathrm{F}_{2}$, either score 0 or 1 , was in agreement with the single-gene model as it appeared in the $F_{2}$ (Table $2)$. However, the separation point at score $0(P=0.69)$ gave a better fit than score $1(P=0.51)$, which was similar to the phenotypic segregation in the $\mathrm{F}_{2}$. Therefore, considering all the segregation of $\mathrm{R}$ and $\mathrm{S}$ in $\mathrm{F}_{2}$ and both $\mathrm{BC}_{1}$ populations, one single recessive gene was responsible for the resistance to anthracnose at mature green fruit stage in the cross between $C$. baccatum $\mathrm{PBC} 80$ and PBC1422.
Anthracnose resistance at ripe fruit stage. The disease scores on the parents, $\mathrm{PBC} 80$ and $\mathrm{PBC} 1422$, at ripe fruit stage were 0 and 5, respectively, also similar to those at mature green fruit stage. However, in contrast to the $F_{1}$ scores on the mature green fruit, the $\mathrm{F}_{1}$ plants were not infected (score 0), resembling the resistant parent $\mathrm{PBC} 80$ (Table 2; Fig. 1). The reciprocal $\mathrm{F}_{1} \mathrm{~s}$ were also resistant (data not shown). The result in the $\mathrm{F}_{1}$ suggested that the resistance to anthracnose at ripe fruit stage was a dominant trait.

The disease score distribution in the $F_{2}$ was skewed toward PBC80, with the majority of the population showing score 0 and a small portion showing scores 1 to 5 . The distribution of the scores at ripe fruit stage also suggested a single-gene model with two phenotypic classes (i.e., $\mathrm{R}$ and $\mathrm{S}$ ). Similarly to the $\chi^{2}$ test at green fruit stage, the segregation of $\mathrm{R}$ and $\mathrm{S}$ fitted a 3:1 Mendelian segregation ratio at either score 0 or 1 as phenotypic separation points (Table 3 ). However, the better fit was derived from the separation point at score $0(P=0.67)$.

The segregation of $\mathrm{R}$ and $\mathrm{S}$ in both $\mathrm{BC}_{1}$ populations at either score 0 or 1 supported the 3:1 segregation ratio in the $\mathrm{F}_{2}$ (Table 3 ), with equal $P$ values of 0.92 . In this case, only one plant had score 1 (data not shown). Therefore, all the segregations of $\mathrm{R}$ and

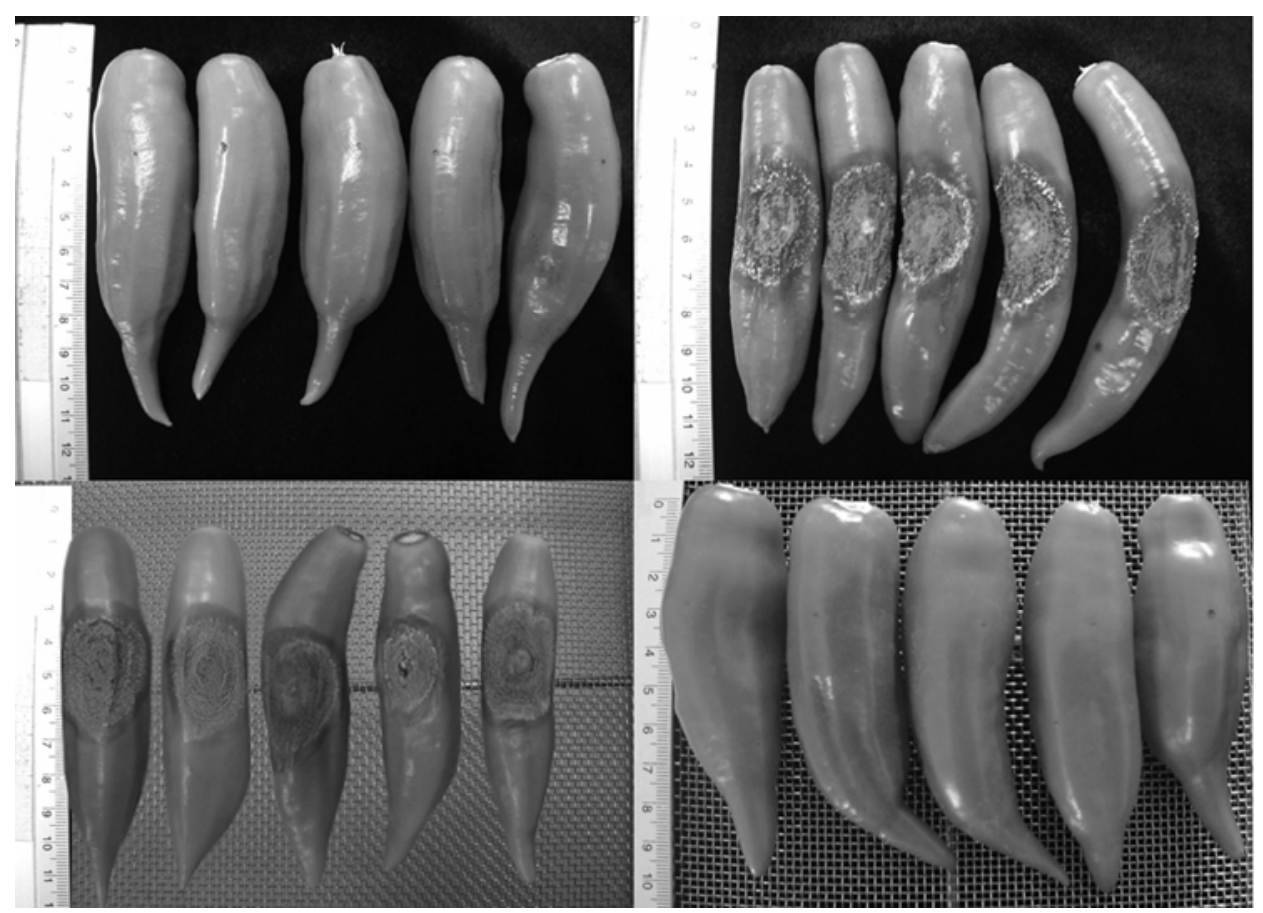

Fig. 1. Anthracnose symptoms on chili fruit at 12 days after inoculation with Colletotrichum acutatum MJ5. Top left, resistance reaction (score 0) on PBC80; top right, susceptibility reaction (score 5) on $\mathrm{PBC} 1422$; bottom left, susceptibility reaction (score 5) on $\mathrm{F}_{1}$ at mature green fruit stage; bottom right, resistance reaction (score 0$)$ on $\mathrm{F}_{1}$ at ripe fruit stage.

TABLE 3. Phenotypic segregation for resistance (R) and susceptibility (S) to anthracnose as inoculated by Colletotrichum acutatum 'MJ5' at ripe fruit stage in 'PBC80' $\left(\mathrm{P}_{1}\right)$, 'PBC1422' $\left(\mathrm{P}_{2}\right), \mathrm{F}_{1}, \mathrm{~F}_{2}$, and $\mathrm{BC}_{1}$ populations as evaluated by contingency $\chi^{2}$ values to fit a Mendelian 3:1 single gene model in the $\mathrm{F}_{2}$ and $1: 1$ in the $\mathrm{BC}_{1} \mathrm{P}_{1}$ populations ${ }^{\mathrm{a}}$

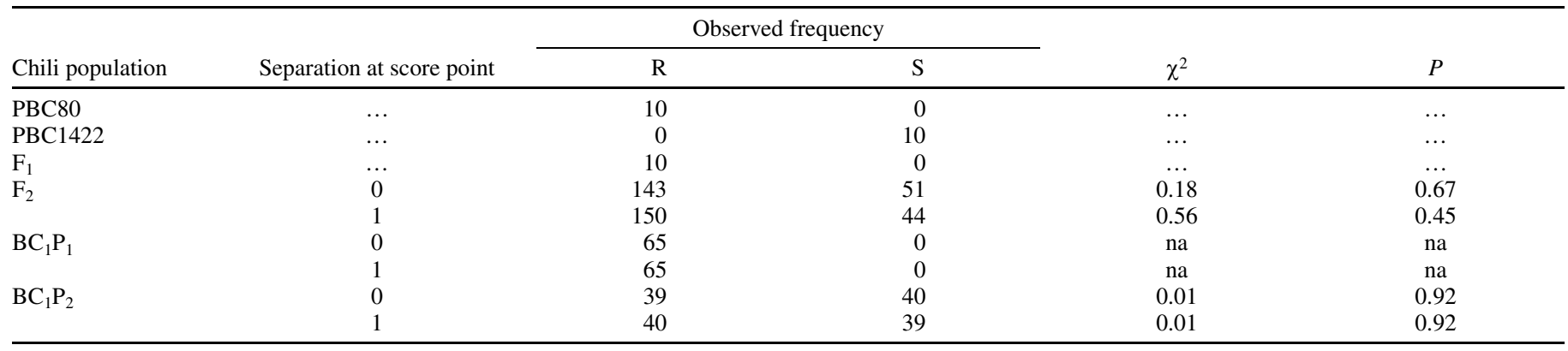

${ }^{\mathrm{a}}$ na $=$ not applicable. 
$\mathrm{S}$ in $\mathrm{F}_{2}$ and both $\mathrm{BC}_{1}$ populations suggested that one single dominant gene was responsible for the resistance to anthracnose at ripe fruit stage in this cross.

Linkage analysis between the resistances at mature green and ripe fruit stages. The inheritance study of the resistance to anthracnose at two different fruit maturity stages suggested that a recessive gene was responsible for the resistance on mature green fruit and a dominant gene was responsible for the resistance on ripe fruit. Combination of the two genes generated four phenotypes, as follows: (i) $\mathrm{R}$ at ripe and $\mathrm{S}$ at green, (ii) $\mathrm{R}$ at ripe and $\mathrm{R}$ at green, (iii) $\mathrm{S}$ at ripe and $\mathrm{S}$ at green, and (iv) $\mathrm{S}$ at ripe and $\mathrm{R}$ at green.

On this basis, if any two genes are independent, the segregation of the four phenotypes will fit 9:3:3:1. Because not all plants yielded both mature green and ripe fruit for inoculation, there were $183 \mathrm{~F}_{2}$ plants used for linkage analysis. Score 0 was chosen to be the phenotypic separation point. The goodness-of-fit test showed a $\chi^{2}$ value of 5.73 with $P$ value $=0.13$, suggesting that resistance genes in both green and ripe fruit were independent (Table 4).

\section{DISCUSSION}

The pathogenicity study on the three chili genotypes suggested that $C$. baccatum PBC80 possessed a wider spectrum of resistance to anthracnose than $C$. chinense. The Colletotrichum capsici isolates did not infect the three chili genotypes at the mature green fruit stage; however, these isolates did infect Bangchang, the susceptible check cultivar, at both fruit maturity stages. Also, to a broader range of chili hosts, the isolates could infect Capsicum annuum, C. frutescens, and some $C$. chinense genotypes (O. Mongkolporn, unpublished data). There appeared to be two pathotypes of Colletotrichum capsici infecting PBC932, because there was a differential reaction between mature green and ripe fruit maturity stages. All the isolates except for 158ci were similar to pathotype PCc1 (10) that could infect the ripe fruit. Montri et al. (10) also reported that PCc 2 and PCc 3 could not infect the ripe fruit stage of PBC932. PBC932 was highly susceptible to all isolates of $C$. acutatum at both fruit maturity stages.

Isolate $158 \mathrm{ci}$ was a different pathotype that could not infect the ripe fruit of PBC932, which may be similar to PCc 2 or PCc 3 as described by Montri et al. (10). The lack of infection by all isolates at the mature green fruit stage indicates the existence of a new 'green fruit' pathotype of $C$. capsici.

From the perspective of chili breeding for anthracnose resistance, PBC932 will not be practically useful in the chili production area where $C$. acutatum is the predominant pathogen. Of the Capsicum baccatum genotypes, PBC80 was very resistant to both Colletotrichum capsici and $C$. acutatum at both maturity stages, whereas PBC1422 was only resistant to $C$. capsici at both fruit maturity stages. Thus, PBC80 appears to have more durable resistance and should be incorporated into breeding programs.

The inheritance study of resistance to anthracnose caused by $C$. acutatum in the intraspecific Capsicum baccatum populations identified two new independent genes responsible for the resis-

TABLE 4. Independence analysis of the genes co4 and Co5 that confer resistance to anthracnose at mature green and ripe fruit stages in the $F_{2}$ population derived from $\mathrm{PBC} 80 \times \mathrm{PBC} 1422^{\mathrm{a}}$

\begin{tabular}{lrr}
\hline Phenotypes $^{\mathrm{b}}$ & $E$ & $O$ \\
\hline $\mathrm{R}$ at ripe, $\mathrm{S}$ at green fruit & 102.94 & 93 \\
$\mathrm{R}$ at ripe and green fruit & 34.31 & 41 \\
$\mathrm{~S}$ at ripe and green fruit & 34.31 & 42 \\
$\mathrm{~S}$ at ripe, $\mathrm{R}$ at green fruit & 11.44 & 7 \\
\hline
\end{tabular}

${ }^{a}$ Phenotypic segregation model for two independent genes is $9: 3: 3: 1$. E = expected frequency and $\mathrm{O}=$ observed frequency; $\chi^{2}=5.73$ and $P=0.13$.

${ }^{\mathrm{b}} \mathrm{R}=$ resistance phenotype and $\mathrm{S}=$ susceptibility phenotype. tances at different fruit maturity stages. One of the genes was a recessive gene and appeared to be expressed at mature green fruit stage. The other was a dominant gene, which appeared to be expressed at ripe fruit stage. These two genes appeared to be different from those previously identified in C. chinense PC932 $(9,12)$. Considering the gene-for-gene hypothesis by Flor $(1)$, the differential reactions found in $\mathrm{PBC} 932$ and $\mathrm{PBC} 80$ inoculated with the same Colletotrichum isolate suggested that the two chili genotypes carried different resistant genes. Therefore, because the three resistance genes identified from PBC932 were designated col, co2, and co3, the newly identified genes from PBC 80 will be designated $\mathrm{CO}_{4}$ and $\mathrm{Co}$. Gene $\mathrm{co} 4$ is the recessive gene identified in mature green fruit while Co5 is the dominant gene identified in ripe fruit.

The classification of $\mathrm{R}$ and $\mathrm{S}$ in this study could be separated at either score 0 or 1 , with a better fit obtained from score 0 . This was in agreement with previous genetic studies of Colletotrichum capsici resistance in PBC932 conducted by Pakdeevaraporn et al. (12) and Mahasuk et al. (9). More convincingly, the separation point was at score 0 due to the better goodness-of-fit analysis obtained from score 0 . The resistance characteristics of both PBC932 and PBC80 were similarly defined as immune resistance. In other words, the immune resistance reacted hypersensitively to the pathogen, whereby no anthracnose symptoms occurred with very little tissue necrosis and localized cell death surrounding the inoculation wound, similar to that found on the leaf of PBC932 (9).

The identification of the genes responsible for the anthracnose resistance in PBC80 will be of great benefit for the development of molecular markers for trait selection in the future. Although interspecific hybridization between Capsicum annuum and $C$. baccatum is not generally practical, development of molecular markers from the intraspecific populations will be useful. A major obstacle to developing markers from interspecific populations is that of large-scale marker distortion and nonsegregating markers $(3,8,11,13)$.

\section{ACKNOWLEDGMENTS}

We thank the Thailand Research Fund and the Center for Agricultural Biotechnology for partial support to this project. The National Center for Genetic Engineering and Biotechnology, National Science and Technology Development Agency granted a Master's student scholarship. Field experiments were supported by the Tropical Vegetable Research Center, Kasetsart University, Kamphaeng Saen Campus.

\section{LITERATURE CITED}

1. Flor, H. H. 1955. Host-parasite interaction in flax rust-its genetics and other implications. Phytopathology 45:680-685.

2. Kanchana-udomkan, C., Taylor, P. W. J., and Mongkolporn, O. 2004. Development of a bioassay to study anthracnose infection of chili fruit caused by Colletotrichum capsici. Thai J. Agric. Sci. 37:293-297.

3. Kang, B. C., Nahm, S. H., Huh, J. H., Yoo, H. S., Yu, J. W., Lee, M. H., and Kim, B. D. 2001. An interspecific (Capsicum annuum $\times$ C. chinense) $\mathrm{F}_{2}$ linkage map in pepper using RFLP and AFLP markers. Theor. Appl. Genet. 102:531-539.

4. Kim, S. H., Yoon, J. B., Do, J. W., and Park, H. G. 2007. Resistance to anthracnose caused by Colletotrichum acutatum in chili pepper (Capsicum annuum L.). J. Crop Sci. Biotechnol. 10:277-280.

5. Kim, S. H., Yoon, J. B., Do, J. W., and Park, H. G. 2008. A major recessive gene associated with anthracnose resistance to Colletotrichum capsici in chili pepper (Capsicum annuum L.). Breed. Sci. 58:137-141.

6. Kim, S. H., Yoon, J. B., and Park, H. G. 2008. Inheritance of anthracnose resistance in a new genetic resource, Capsicum baccatum PI594137. J. Crop Sci. Biotechnol.11:13-16.

7. Lin, Q., Kanchana-udomkan, C., Jaunet, T., and Mongkolporn, O. 2002. Genetic analysis of resistance to pepper anthracnose caused by Colletotrichum capsici. Thai J. Agric. Sci. 35:259-264.

8. Livingstone, K. D., Lackney, V. K., Blauth, J. R., Wijk, R. v., and Jahn, M. K. 1999. Genome mapping in Capsicum and the evolution of genome structure in the Solanaceae. Genetics 152:1183-1202. 
9. Mahasuk, P., Khumpeng, N., Wasee, S., Taylor, P. W. J., and Mongkolporn, O. Inheritance of resistance to anthracnose (Colletotrichum capsici) at seedling and fruiting stages in chili pepper (Capsicum spp.). Plant Breed. Online. doi: 10.1111/j.1439-0523.2008.01615.x.

10. Montri, P., Taylor, P. W. J., and Mongkolporn, O. 2009. Pathotypes of Colletotrichum capsici, the causal agent of chili anthracnose, in Thailand. Plant Dis. 93:17-20.

11. Onus, A. N., and Pickersgill, B. 2000. Monogenic segregations in backcross progenies of Capsicum baccatum $\times$ two interspecific $\mathrm{F}_{1}$ hybrids and some possible explanations for distorted segregation ratios in Capsicum. Turk. J. Bot. 24:319-328.

12. Pakdeevaraporn, P., Wasee, S., Taylor, P. W. J., and Mongkolporn, O. 2005. Inheritance of resistance to anthracnose caused by Colletotrichum capsici in Capsicum. Plant Breed. 124:206-208.
13. Prince, J. P., Pochard, E., and Tanksley, S. D. 1993. Construction of a molecular linkage map of pepper and a comparison of synteny with tomato. Genome 36:404-417.

14. Than, P. P., Rajesh, J., Hyde, K. D., Pongsupasamit, S., Mongkolporn, O., and Taylor, P. W. J. 2008. Characterization and pathogenicity of Colletotrichum species associated with anthracnose infection on chili (Capsicum spp.). Plant Pathol. 57:562-572.

15. Voorrips, R. E., Finkers, R., Sanjaya, L., and Groenwold, R. 2004. QTL mapping of anthracnose (Colletotrichum spp.) resistance in a cross between Capsicum annuum and C. chinense. Theor. Appl. Genet. 109:1275-1282.

16. Yoon, J. B., and Park, H. G. 2005. Trispecies bridge crosses, (Capsicum annuиm $\times$ C. chinense $) \times C$. baccatum, as an alternative for introgression of anthracnose resistance from $C$. baccatum into $C$. annuum. J. Korean Soc. Hortic. Sci. 46:5-9. 